\title{
A DEMONOLOGIA DA IGREJA UNIVERSAL DO REINO DE DEUS
}

\author{
Ari Pedro Oro ${ }^{1}$
}

O texto de Jaçanã Ribeiro, apresentado na primeira parte deste Debates do NER, mostra com especial sutileza e grande capacidade analítica, como a figura do demônio ocupa um lugar privilegiado no corpus discursivo iurdiano e em vários de seus rituais, sobretudo na chamada "sessão espiritual do descarrego". A importância do demônio é tal que pode-se falar em demonologia iurdiana ${ }^{2}$. Aproveito, então, este espaço, embora limitado, para apresentar um esboço desse tema, que deverá ser aprofundado no futuro.

\section{A DEMONIZAÇÃO DO OUTRO}

A demonologia iurdiana resulta da realização de dois movimentos. De um lado, a recuperação e aceitação das representações e concepções acerca das forças maléficas que acompanham a própria história do cristianismo, e, de outro lado, a identificação das forças do mal sobretudo nas entidades espirituais que compõem o panteão das religiōes afro-brasileiras. Neste sentido, a Universal em certo sentido inova, a partir de um sistema de crenças pré-existente. Veremos como se dão esses dois movimentos.

A representação de uma figura invisível associada ao mal - denominada demônio, diabo e satanás, simultaneamente nas tradições helênica,

\footnotetext{
${ }^{1}$ Professor do Departamento de Antropologia e do Programa de Pós-Graduação em Antropologia Social da Universidade Federal do Rio Grande do Sul.

2 Demonologia, como se sabe, consiste no estudo dos demônios, seus poderes e atributos correspondentes a cada entidade maléfica, e suas relações com os humanos.
}

Debates do NER, Porto Alegre, ano 6, N. 7, P. 135-146, JAn./Jun. 2005 
hebraica e cristã - tornou-se uma das figuras centrais do imaginário cristão ocidental, fazendo "surgir uma nova linha de especulação, com a autoridade de ciência - a demonologia - e os teólogos passam a se preocupar em estabelecer, com a máxima clareza, o seu perfil e caráter, num esforço piedoso para auxiliar a Cristandade a reconhecer o Inimigo e se precaver contra ele" (Nogueira, 2000, p. 61).

É sobretudo no fim da Idade Média e no início dos tempos modernos que

"o inferno e seus agentesdominaram de modo global a imaginação dos homens do Ocidente. Com a difusão da imprensa, obra após obra, em diferentes países, acrescenta, com um luxo de detalhes e explicações jamais vistas, todas as idéias e particularidades que uma fantasia sem barreiras desenvolvera sobre a personalidade, os poderes e os aspectos do inimigo do gênero humano" (Id. Idib., p. 98).

Desde o século XVIII, no entanto, a teologia católica

"tornou-se cada vez mais econômica nas questões demonológicas, as quais foram, por sua vez, apropriadas pelas forças periféricas: ocultistas, satanistas, amadores, grupos sectários marginais, algumas personalidades (...). A teologia liberal, católica e protestante, simplesmente evita o mundo demoníaco, ou menciona-o apenas como uma metáfora, um símbolo tradicional, uma abstração" (Kolakowski, 1985:20).

Ainda no âmbito católico, principalmente após o Concílio Vaticano II,

"não existe mais uniformidade na doutrina sobre satanás e os demônios. Muitos teólogos colocam em dúvida a existência do diabo ou se manifestam positivamente contra ela. Outros procuram interpretar de maneira nova a tradição demonológica da Igreja católica (...). Parte dos teólogos ainda mantém a doutrina tradicional e muitos católicos ainda estão sob sua influência ou se confessam abertamente adeptos dela" (Wenisch, 1992:41). 
Referindo-seao comportamento atual da Igreja Católica diante da crença em satanás Danièle Hervieu-Léger nota, não sem surpresa, um certo deslocamento desta instituição, pois, como veremos mais à frente, enquanto, de um lado, tal crença tende a aumentar na sociedade moderna, de outro, a igreja católica, que durante séculos chamou para si a gestão das representações das forças maléficas sobre o mundo, reduziu sua presença na catequese e na pregação; substituiu, em 1972, no antigo ritual dos moribundos (a extrema-unção) a representação do combate entre Jesus e Satanás no leito do moribundo pela reunião da comunidade com Jesus diante de um de seus membros sofredor; e, enfim, diante do aumento das demandas por exorcismos notou-seque algumasdioceses não possuíamum exorcista oficial, e muitos que foram nomeados a este título entendiam exercer um papel de apoio espiritual e psicológico, ou mesmo psiquiátrico, ao invés de exerceruma atividadepropriamente ritual (Hervieu-Léger, 1999, pp. 49-50).

No catolicismo popular, porém, segundo E. D. B. de Menezes, o diabo, implícita ou declaradamente, sempre constituiu um dos personagens centrais, sendo o móvel fundamental na explicação dos eventos, das situações e dos comportamentos (Menezes, 1981, p. 4).

Relativamente aos evangélicos, há, no dizer de Wenisch, uma dupla apreciação sobre o tema: de um lado, os teólogos liberais, que se distanciaram da tradicional demonologia cristã bem mais cedo do que os teólogos católicos, e, de outro lado, os fundamentalistas, que sempre mantiveram a crença de que os espíritos demoníacos se imiscuem diretamente na história do mundo (Wenisch, 1992, pp. 42 e ss).

É este último também o posicionamento doutrinário do pentecostalismo e do neopentecostalismo brasileiros. De fato, para eles,

"tanto é o diabo que causa as doenças, conflitos, desempregos, alcoolismo, leva ao roubo ou a qualquer crime, como é Jesus e o Espírito Santo que cura, acalma, dá saúde, dá prosperidade material e liberta do vício e do pecado. Nesta visão se nega assim por um lado a ação de outros seres espirituais como se nega a responsabilidade humana e consequentemente as origens históricas do mal e do bem" (Mariz, 1997, p. 231). 
Ora, a Igreja Universal do Reino de Deus também reconhece a importância dos demônios como causadores dos males e problemas de toda ordem que afetam as pessoase a sociedade. Eles são tidos como os perturbadores da "ordem 'natural' das coisas ("natural" no sentido daquilo que está conforme a vontade divina), cujo objetivo é "distrair Deus" (Gomes, 1994, pp. 233-234). A este respeito escreveu Edir Macedo, o fundador da Igreja Universal, em seu livro best seller: "Orixás, Caboclos e Guias: deuses ou demônios" 3 : "Tudo o que existe de ruim neste mundo tem sua origem em satanás e seus demônios. São eles os causadores de todos os infortúnios que atingem o homem direta ou indiretamente" (Macedo, 1987, p. 103). Em outro livro ele se questiona, e responde: "Qual a origem de todos os males que afligem a humanidade? Doenças, misérias, desastres e todos os problemas que têm afligido o homem desde que este iniciou sua vida na terra, têm uma origem: o diabo" (Macedo, 1995, p. 43)4. Portanto, para a Universal, "o diabo não é somente a antítese (o arquiinimigo) de Deus. Ele é a encarnação do Mal; uma presença constante (e ameaçadora) na vida e no cotidiano das pessoas" (Barros, 1995, p. 146). Disso resulta que as representações do diabo "constituem o eixo a partir do qual o universo simbólico desta igreja é construído..." (Id. Idib. p.1).

Porém, a IURD, além de assumir esta representação relativamente generalizada do poder do demônio, vai exacerbar uma concepção já presente

\footnotetext{
${ }^{3}$ Trata-se de um livro escrito em 1987, dedicado "a todos os pais-de-santo e mães-de-santo de nossa pátria” e que já vendeu mais de dois milhões de exemplares. Este mesmo livro foi também editado em CD-ROM, pela Universal Produções. Edir Macedo, escreveu, em 1995, mais u m livro sobre o tema dos demônios: "O diabo e seus anjos". Nele sustenta a mesma acusação demoníaca em relação ao panteão religioso afro-brasileiro.

${ }^{4}$ Por isso mesmo, é recorrente nos templos universais afirmações como estas por parte dos pastores: "tu demônio que amarrou os negócios; demônio que atua no trabalho dele; demônio que amarrou a empresa; demônio da dívida; demônio da falência; demônio da doença; demônio que vem atuando sobre esta pessoa causando toda espécie de problema; demônio que está destruindo a saúde, a finança, a família; é o demônio que está alojado nesta pessoa; nenhum médico resolve o problema dele, só a libertação em nome do Senhor Jesus".
} 
nas igrejas católica, evangélicas e pentecostais, embora ali ocorra de forma mais branda, qual seja, a identificação demoníaca nas figuras das entidades das religióes mediúnicas, sobretudo das afro-brasileiras ${ }^{5}$.

Aqui radica o segundo movimento realizado pela Igreja Universal no processo de construção da sua demonologia. Ouçamos o que diz o seu fundador: "a Umbanda, Quimbanda, Candomblé e o espiritismo de um modo geral, são os principais canais de atuação dos demônios, principalmente em nossa pátria" (Macedo, 1987, p. 113). Em outro momento do mesmo livro, escreve:

"Com nomes bonitos e cheios de aparatos, os demônios vêm enganando as pessoas com doutrinas diabólicas. Chamam-se orixás, caboclos, pretos-velhos, guias, espíritos de luz, etc. Dizem-se ser exus, erês, espíritos de crianças, médicos famosos, poetas famosos, etc., mas na verdade são anjos decaídos" (Macedo, 1987, p. 32).

Além disso, acrescenta: "Essa religião (afro-brasileira) que está tão popular no Brasil é uma fábrica de loucos e uma agência onde se tira o passaporte para a morte e uma viagem para o inferno" (Macedo, 1987, p. 86). Seus centros seriam "morada de demônios"; seus deuses "espíritos malignos", seus cultos "rituais do demônio"; seus líderes religiosos "serviçais do diabo"; seus fiéis e clientes "pessoas ignorantes que caíram na armadilha de satanás".

Portanto, "orixás, caboclos, pretos-velhos, guias, espíritos de luz (...), exus, erês, espíritos de crianças, médicos famosos, poetas famosos”... são

5 Como recorda R. Mariano (1995, p. 98), "há muito tempo os rituais, as crenças, os deuses e guias dos cultos afro-brasileiros e espíritas são percebidos e classificados como demoníacos pelos evangélicos e até por algun s expoentes da Igreja Católica”. Ta mbém C. Mariz escreve que "... a crença de que existem religiōes demoníacas e de que as religiōes espíritas e afro-brasileiras são demoníacas, alem de ser geral no universo evangélico brasileiro, es tá ta mbém presen te no catolicismo, especialmente entre os grup os car ismáticos" (Mariz, 1997, p. 34). 
estes os demônios, identificados pela IURD, que se apossam das pessoas. Por isso mesmo, a Universal vai se atribuir a missão de combatê-los para libertar as pessoas". É novamente Edir Macedo quem escreve: "nossa igreja foi levantada para um trabalho especial (...) a liber tação de pessoas endemoninhadas" (Id. Ibid. p. 16). E completa: "Lidamos com esse tipo de coisa há alguns anos e três ou quatro vezes por dia, de segunda a segunda, estamos preocupados em libertar as pessoas de toda a obra do diabo" (Id. Ibid., p. 46). Em outras palavras, o fundador da IURD está dizendo que sua igreja nasceu para a "guerra espiritual" . E mais, a sua estratégia é não ficar na defensiva, na retaguarda, esperando que os inimigos, os demônios ataquem, mas agir na ofensiva, na vanguarda, antecipando-se à ação deles. Escreve Macedo:

"Muitos cristãos vivem pedindo oração porque estão sendo perseguidos pelo diabo. É de estarrecer, porque a realidade deveria ser outra. Os cristãos é que devem perseguir os demônios. Nossa luta é muito mais de combate do que de defesa; devemos nos armar de toda a armadura de Deus para libertar os oprimidos. A igreja deve ser triunfante e estar sempre na ofensivà (Macedo, s/d, p. 114).

Poisé justamente a ausência da luta contra os demônios que E. Macedo vai recriminar às outras denominações evangélicas que, segundo ele, "pregam apenas o evangelho 'chocolate', ou 'água com açúcar', e não libertam verdadeiramente as pessoas da influência dos demônios” (Macedo, 1987,

\footnotetext{
${ }^{6}$ O termo "libertar", ou "liber tação", éfundamental mas ambíguo na Universal. D. Lehman n assinala que ele tem um duplo significado: "libertar os indivíduos dos diabos que os possuem mas também libertar o mau espírito que está dentro do indivíduo cujo corpo em certo sentido o aprisiona” (Lehmann, 1996, p. 139).

${ }^{7}$ Segundo R. Mariano, a IURD não é a única igreja evangélica implicada na "guerra santa”. Alem dela, pode-se citar a Igreja Internacional da Graça de Deus, Igreja do Espírito Santo (dissidência da IURD no Nordeste), Cristo Vive, Comunidade Evangélica, Casa da Bênção e Igreja Deus é Amor (Mariano, 1995, pp. 103-104).
} 
p. 113). Por isso, continua o fundador da Universal: "temos de sair da mera pregação pentecostal, que está na moda, para a pregação plena” (Id., Ibid., p. 131).

Na prática isto significa que a IURD desde a sua fundação conduz um ataque sem trégua, contumaz, radical, contra as religiões afro-brasileiras, a tal ponto que esse combate "tornou-se um de seus principais pilares doutrinários” (Mariano, 1995, p. 103).

De fato, os vilipêndios contra os afro-brasileiros aparecem desde a fundação da Igreja. Nos primeiros anos da igreja os vilipêndios eram declarados e diretos, como este que colhi num templo em Porto Alegre no início dos anos 80:

“Tu, espírito imundo, que foi pago no cemitério, na cachoeira. Isto é obra de macumbaria, feitiçaria. Omolu está aqui de joelho (...). Você que vai consultar Maria Mulambo, olha ela aqui de joelhos na Igreja Universal (...). A Macumba é uma porcaria e nós vamos lutar contra esta porcaria até o fim (...). $\mathrm{Na}$ Macumba tem uma legião de demônios; estes demônios da macumba só querem roubar, matar, destruir (...). Ele é um exu em forma de caboclo".

Se as acusações diretas tenderam a diminuir na mídia iurdiana, em razão de pressões, elas continuam nos templos mediante o ritual performático do exorcismo onde as entidades das religiōes afro-brasileiras são invocadas a "se manifestarem" para en tão serem humilhadas e, posteriormente, exorcizadas. Isto ocorre mediante um processo de entrevista com os "demônios" que obedecem, basicamente, a "três perguntas-chave, que revelam a origem, os males causados e a maneira pela qual o demônio entrou no corpo do endemoninhado" (Almeida, 2003, p. 326). Este ritual, reconhece Edir Macedo, constitui o "lugar central no culto" (Macedo, 1995, p. 36). Nele, "os demônios são humilhados e até mesmo achincalhados" (Macedo, 1987, p. 134). É Deus, continua o fundador da IURD, que "permite que os demônios se manifestem para que sejam envergonhados e, principalmente, desmascarados" (Macedo, 1987, p. 136).

Embora manifestações demoníacas ocorram quase que diariamente nos 
templos iurdianos, é especialmente nas terças-feiras, nas "Sessões Espirituais de Descarrego", e nas sextas-feiras, nas "Reuniōes, ou correntes, de Libertação", que os rituais de exorcismo são fartamente reprod uzidos. Nestes casos, como lembra Ronaldo de Almeida, a libertação acaba assumindo estruturalmente o papel de um contra-feitiço diante do feitiço das religiões afro-brasileiras, que reconhecem e aceitam a veracidade (Almeida, 2003, p. 332).

Enfim, nessas sessões, e em outras, a importância atribuída ao panteão das religiões afro-brasileiras, mesmo que re-semantizado, é tal que ele passa a integrar o próprio sistema de crenças e da ritualística da IURD. "Isto é, não só os ex-praticantes das religiōes afro-brasileiras comparecem aos cultos da Universal, mas também suas antigas divindades, ainda que transformadas" (Almeida, 2003, p. 337). Isto significa que várias entidades do campo afro já fazem parte do universo iurdiano, embora tenham recebido atribuições específicas e, evidentemente, "relacionadas a males concretos da vida” (Id. Ibid. 39). Assim, recorda Ronaldo de Almeida, que

"segundo os pregadores (da IURD), a Pombagira, por representar uma prostituta e por levar as pessoas ao homossexualismo, é a causador a da Aids; o Preto-Velho, por andar curva, causa as dores da coluna; o Exu Tranca-Rua gera a miséria; os erês atingem fisicamente as crianças; o Exu da Morte, por sua vez, motiva o suicídio" (Almeida, 2003, pp. 339-340).

\section{O CULTO AO DEMÔNIO NA MODERNIDADE}

A importância detida pelo demônio na Igreja Universal não constitui uma situação excepcional. Ela se inscreve dentro de um contexto maior de aumento, mesmo em tempos de desmagicização das sociedades modernas racionais, de crenças em demônios, anjos, milagres, duendes etc, crenças estas que parecem reaparecer em todo o mundo (Gapp, 2000), independentemente das camadas sociais e do status detido por uma sociedade ou nação. Vejamos alguns dados, a título de exemplo. 
Segundo a Revista Veja, 44\% dos brasileiros acreditam no inferno, do que se infere ser provavelmente percentagem semelhante dos que crêem na existência do demônio (Revista Veja, 2/4/1997). Tal afirmação pode ser feita baseada em outra pesquisa, realizada em 2002 e 2003, junto a estudantes de instituiçóes do ensino superior públicas e privadas de Porto Alegre, Rio de Janeiro e São Luis do Maranhão, onde constatou-se que o percentual dos que crêem no demônio é de $40,4 \%$, sendo que a crença no inferno praticamente coincide com a de demônios, 39,4\% (Oro, 2004, pp. 75-79).

Já a média européia da crença no inferno era, em 1990, de 23\% dos cidadãos consultados, de 15 países, divididos entre países católicos, pluriconfessionais e luteranos (Pace, 1998). No entanto, em alguns países, como a França, por exemplo, a crença no demônio está aumentando. É o que afirma D. Hervieu-Léger. Diz ela: há um "aumento da crença no diabo na França contem porânea" (Hervieu-Léger, 1999, p. 49). Esta afirmação é comprovada pela revista l'Express, que divulgou recentemente um dossiê intitulado "A loucura do esoterismo". Nela refere, por exemplo, uma pesquisa realizada pelo sociólogo Yves Lambert que revela ter havido um crescimento na crença no inferno entre os jovens de 19 a 28 anos. Eram 11\% em 1981 e são 21\% em 1999 (Revista l'Express, N. 2816, 20-26/6/2005).

Por outro lado, é importante assinalar que não é somente a crença em demônios, anjos ou duendes, que está aumentando. Constata-se na modernidade o que alguns chamam de "retorno do sagrado", "revanche de Deus", "retorno do oculto e do sobrenatural", que se expressa na multiplicação de comunidades religiosas alternativas, no surgimento e pulverização de lojas com produtos religiosos de toda ordem, no crescimento do número de sites que versam sobre "ciências esotéricas", no espantoso aumento da literatura esotérica, no lançamento de filmes e de produtos midiáticos baseados nesse tema, no surgimento de indivíduos especializados nas artes divinatórias, tudo isto caracterizando, como diz a revista francesa acima mencionada, a "grande revanche do irracional, do impenetrável e do hermético: o triunfo do esoterismo" (Revista l'Express, 2005, p. 30).

Mas, voltando ao tema da crença no demônio na modernidade, Gapp 
sugere que o "retorno do diabo" ocorre em reação à crise das formas tradicionais do religioso, como uma exacerbação da religiosidade fora dos seus quadros institucionais (Gapp, 2000). Por seu turno, Nogueira sustenta que

"Práticas e cultos satânicos representam uma saída possível, seja para os arquetípicos problemas amorosos, para a obtenção de riqueza, da tão almejada saúde e felicidade, para fins políticos ou então como uma forma de lazer que possa iluminar a monotonia de um cotidiano insípido e rejeitado. Solução ideal porquanto de foro íntimo, que apresenta fórmulas de superação ou escape de uma realidade caracterizada pela ausência de projetos coletivos, de teorias políticas, ou de um otimismo social que nos possibilite enxergar na turbulência do vivido, uma esperança de melhoria e na escuridão do futuro, a sobrevivência de um mundo racional e progressista que parece a todo momento, na iminência de desmoronar" (Nogueira, 2000, p. 115).

Enfim, segundo Danièle Hervieu-Léger, tal crença mantém relação com a experiência quotidiana que os indivíduos detém da complexidade do mundo atual onde não encontram mais suas referências e onde experimentam o sentimento de estar submetidos a forças que os ultrapassam e que não conseguem captar. Esta experiência é ainda mais traumatizante devido ao fato de que se vive na atualidade numa sociedade que alimenta midiaticamente a utopia de acesso aos principais bens de consumo, tais como saúde, bem-estar, realização de si, saúde eterna, segurança. Além disso, tais frustrações psicológicas e sociais são exacerbadas pela crise econômica, a desqualificação do político e a ausência de perspectivas. Neste sentido, continua a Autora, "crer no diabo é uma maneira de exteriorizar este sentimento de impotência, identificando, para além do mal estar pessoal, a ação de uma potência má que manipula e "possui" as pessoas" (Hérvieu-Léger, 1999, p. 51). Neste quadro, o diabo é sempre apreendido como uma "força negativa" que se experimenta e sobre a qual se pode agir com técnicas apropriadas, postas em prática por especialistas. Enfim, nota a autora, existir correspon dências entre o "retorno do diabo" e as diversas modalidades de diabolização do outro (o estrangeiro, o Árabe ou o Judeu, mas também os tecnocratas, os políticos) (Id. Ibid., p. 52). 
Esta última afirmação se aplica perfeitamente ao caso aqui analisado, onde nota-se uma relação entre a exacerbação da figura do demônio por parte da Igreja Universal do Reino de Deus e a demonização do outro por parte dessa mesma igreja, ou seja, em larga medida das religiōes afro-brasileiras e do espiritismo, e, em proporção menor, do próprio catolicismo.

\section{REFERENNCIAS}

ALMEIDA, Ronaldo de. A guerra das possessões. In: Oro, A. P., Corten, A. e Dozon, J. P. Igreja Universal do Reino de Deus. Os novos conquistadores da fé. São Paulo, Paulinas, 2003, pp. 321-342.

. A Universalização do Reino de Deus. Dissertação de Mestrado em Antropologia Social apresentada na UNICAMP, 1996.

BARROS, Mônica do Nascimento. "A batalha do Armagedom". Uma análise do repertório mágico-religioso proposto pela Igreja Universal do Reino de Deus. Dissertação de Mestrado, UFMG, Belo Horizonte, 1995.

GAPP, Estelle. "Le festival du Diable”. Revue d'Éthique et de Théologie Morale. N. 212, 2000.

GOMES, Wilson. Nem anjos nem demônios. Petrópolis, Vozes, 1994:225-270.

HERVIEU-LÉGER, Danièle. Le Pèlerin et le Converti. La religion en Mouvement. Paris, Flammarion, 1999.

LEHMANN, David. Struggle for the Spirit. Religious Transformation and Popular Culture in Brazil and Latin America. Cambridge, Polity Press, 1996.

KOLAKOWSKI, L. O diabo. Religião e Sociedade. N. 12/2, 1985.

MACEDO, Edir. A Libertação da Teologia. Rio de Janeiro, Universal Produções, S/D. O diabo e seus anjos. Rio de Janeiro, Ed. Gráfica Universal , 1995.

1987. . Orixás, Caboclos e Guias: deuses ou demônios? Rio de Janeiro, Universal Produções,

MARIANO, Ricardo. Neopentecostalismo: os pentecostais estão mudando. Dissertação de mestrado, FFLCH/USP, 1995.

MARIZ, Cecilia. Reflexôes sobre a reação afro-brasileira à guerra santa. Debates do NER. N. 1, 1997, pp. 95-102.

MENEZES, Eduardo Diathahy. A quotidianidde do demônio na cultura popular. Paper apresentdo no V Encontro anual da ANPOCS, 1981.

Debates do NER, Porto Alegre, ano 6, N. 7, P. 135-146, Jan./Jun. 2005 
NOGUEIRA, Carlos Roberto F. O diabo no imaginário cristão. Bauru, SP, Edusc, 2000.

ORO, Ari Pedro. "Os universitários brasileiros e a religiāo". In: ORO, Ari Pedro (org). Representaçôes sociais e Humanismo latino no Brasil atual. Porto Alegre, Ed. Da Universidade, 2004, pp. 59-90.

Neopentecostais e afro-brasileiros: quem vencerá esta guerra? Debates do NER,

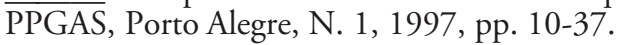

ORO, Ari Pedro; CORTEN, André; DOZON, Jean-Pierre. Igreja Universal do Reino de Deus, os novos conquistadores da fé. São Paulo, Paulinas, 2003.

PACE, Enzo. "O futuro das religiōes na Europa”. Religiāo e Sociedade, V. 19, 1998, pp. 19-28.

WENISCH, Bernhard. Satanismo. Petrópolis, Vozes, 1992.

Debates do NER, Porto Alegre, ano 6, N. 7, p. 135-146, jan./Jun. 2005 
